\title{
Outcome predictors of uncomplicated sepsis
}

\author{
Ewoud ter Avest ${ }^{1 *}$, Maarten de Jong ${ }^{2}$, Ineke Brümmer², Götz JK Wietasch ${ }^{3}$ and Jan C ter Maaten²
}

\begin{abstract}
Background: The development of sepsis risk prediction models and treatment guidelines has largely been based on patients presenting in the emergency department (ED) with severe sepsis or septic shock. Therefore, in this study we investigated which patient characteristics might identify patients with an adverse outcome in a heterogeneous group of patients presenting with uncomplicated sepsis to the emergency department (ED).

Findings: We performed a retrospective cohort analysis of all ED patients presenting with uncomplicated sepsis in a large teaching hospital during a 3-month period. During this period, 70 patients fulfilled the criteria of uncomplicated sepsis. Eight died in the hospital. Non-survivors were characterized by a higher abbreviated Mortality in Emergency Department Sepsis (MEDS) score (7.2 \pm 3.4 vs. $4.8 \pm 2.9, p=0.03)$ and a lower Hb (6.6 \pm 1.2 vs. $7.7 \pm 1.4, p=0.03)$, and they used beta-blockers more often ( $75 \%$ vs. $19 \%, p<0.01)$.

Conclusions: Non-survivors of uncomplicated sepsis had on average a higher abbreviated MEDS score, a lower hemoglobin $(\mathrm{Hb})$ and more often used $\beta$-blockers compared to survivors. Early identification of these factors might contribute to optimization of sepsis treatment for this patient category and thereby prevent disease progression to severe sepsis or septic shock.
\end{abstract}

Keywords: Sepsis, Uncomplicated, Emergency department, Outcome

\section{Introduction}

Sepsis remains an ongoing challenge in medicine. Mortality rates depend on the sepsis stage and co-morbidity and range from $4.1 \%$ in patients with uncomplicated sepsis to as high as $50 \%$ in patients with septic shock [1]. Although patients with severe sepsis or septic shock have a higher a-priori chance of having an unfavorable outcome than patients with uncomplicated sepsis, the latter group is responsible for the majority of sepsis hospitalizations in developed countries [2]. Unfortunately, however, research over the past years has mainly been focused on the early identification and treatment of patients with advanced stage sepsis: Risk prediction models and especially treatment guidelines for sepsis at the ED are largely derived from patients presenting with severe sepsis or septic shock, and it remains unclear whether the same risk prediction models are applicable for patients presenting to the ED with uncomplicated sepsis [3-5]. Therefore, the primary objective of this study was

\footnotetext{
* Correspondence: teravestewoud@hotmail.com

${ }^{1}$ Department of Emergency Medicine, Medical Center Leeuwarden, Henry Dunantweg 2, Leeuwarden 8934 AD, The Netherlands

Full list of author information is available at the end of the article
}

to investigate which patient characteristics are related to outcome in a heterogeneous group of patients presenting with uncomplicated sepsis to the ED.

\section{Methods}

\section{Study design and inclusion criteria}

We performed a retrospective cohort analysis of all adult emergency department (ED) patients (>18 years) who presented to the ED of the University Hospital Groningen with uncomplicated sepsis during a 3-month period (1 September 2010 until 30 November 2010). During this period, a quality improvement initiative had been carried out to improve early sepsis recognition in patients with sepsis at the ED. According to this initiative, for all patients visiting the ED during the study period with sepsis (defined as the presence of two or more SIRS criteria in combination with the suspicion of a new infection), temperature, heart rate, respiration rate, blood pressure and oxygen saturation were recorded at presentation by a trained triage nurse. Ordering of (additional) diagnostic tests and initiation of therapy were both left completely to the discretion of the attending physician.

\section{实 Springer}


In the present retrospective cohort analysis, only patients with non-severe (i.e., uncomplicated) sepsis were enrolled. Uncomplicated sepsis was defined retrospectively by one of the authors $(\mathrm{MdJ})$ as sepsis in the absence of signs of organ dysfunction at a site remote from the site of the infection or sepsis with signs of hypotension or hypoperfusion. Subjects were excluded when one or more of the following criteria were met for not to being considered to have a chronic condition: systolic blood pressure $<90 \mathrm{mmHg}$, or a MAP $<65$ $\mathrm{mmHg}$, creatinine $>177$ umol. $^{-1}$, bilirubin $>34 . \mathrm{mmol}^{-1}{ }^{-1}$, platelet count $<100 \times 10^{9} .1^{-1}$, coagulopathy with INR $>1.5$ or aPTT $>60 \mathrm{~s}$, or a lactate level of $>2 \mathrm{mmol.} \mathrm{l}^{-1}$. A limited life expectancy as a result of underlying disease was not an exclusion criterion in the present study.

\section{Data collection}

Vital signs, biochemical test results, ED treatment characteristics and final outcome were retrieved from the electronic patient files. Abbreviated Mortality in Emergency Department sepsis (MEDS) scores [3] without neutrophil bands [6] (since these are not routinely measured in many Dutch hospitals) were calculated retrospectively from eight independent predictors of mortality, resulting in a maximum score of 24 .

\section{Primary data analysis}

Differences between survivors and non-survivors regarding baseline characteristics were tested for statistical significance by using the two-tailed Fisher's exact test for dichotomous variables and one-way ANOVA for continuous variables, with age, gender, time-to-antibiotics and fluid administration (all variables) and MEDS score (treatment variables) as covariates. It was estimated that with our study population of 70 subjects, a Spearman's correlation coefficient $(r)$ of 0.3 could be detected with a power of $80 \%$ and an alpha error of 0.05 .

\section{Ethics}

As our study only involved retrospective evaluation of routinely recorded patient data, this type of study was determined to be exempt research by our local institutional review board.

\section{Findings}

During the 3-month period, 8,146 patients visited the ED of the University Medical Center Groningen. During this period, 101 patients were diagnosed with sepsis, of which 31 had a severe sepsis or septic shock, and 70 had an uncomplicated sepsis. Further results refer to this latter group.

\section{Clinical and biochemical characteristics at presentation}

Eight patients died in-hospital after presentation to the ED, on average 11 days after presentation (range 4-21). Table 1 shows the clinical and biochemical characteristics at presentation of survivors and non-survivors. The non-survivors were on average 14 years older than the survivors. Although they more often had an underlying medical condition predisposing for sepsis, only one of the non-survivors had a terminal illness (metastatic malignancy) with a life expectancy $<1$ month at the time of presentation (Tables 1 and 2). Non-survivors more often used beta-blockers compared to survivors, while other vasoactive drug use and immunosuppressive drug use were not significantly different between both groups. Lower respiratory tract infections were the prevailing source of sepsis in both survivors (56\%) and nonsurvivors $(75 \%, p=0.77)$. Hemoglobin concentration was the only biochemical parameter that differed significantly between survivors and non-survivors, even after correction for the age difference between both groups. As expected, the mean MEDS score was significantly higher in patients with an adverse outcome compared to survivors. None of the subjects had a MEDS score $\geq 12$ (high-risk group).

\section{Treatment characteristics}

Table 1 shows the treatment characteristics for both survivors and non-survivors. Mean time from presentation at the ED to the administration of the first gift of antibiotics was 87 min (range 15-215 minutes). The average amount of intravenous fluids administered was $680 \pm$ $584 \mathrm{ml}$ in the first $120 \mathrm{~min}$. No significant differences regarding time to antibiotics or the amount of fluid administration during the first $120 \mathrm{~min}$ at the ED were present between survivors and non-survivors, even after correction for the difference in MEDS score between both groups (to correct for possible treatment differences resulting from differences in disease severity).

\section{Association of patient characteristics with outcome}

Of all clinical and biochemical variables at presentation, only beta-blocker use was correlated to outcome with a correlation coefficient $(r)$ larger than the minimum $r$ of 0.3 that could be detected with our study population $(r=-0.40, p<0.001)$.

\section{Discussion}

In our study, we found a mortality rate of $11 \%$, which is higher than several previous studies reported [3,5]. It is unlikely that the higher mortality rate in our study is the result of the inclusion of many subjects suffering from a terminal illness: Only 2 out of 70 subject had a terminal illness and a resulting do-not-resuscitate status. All other subjects received optimal care, including referral to the 
Table 1 Clinical and biochemical characteristics of survivors and non-survivors of uncomplicated sepsis at the emergency department

\begin{tabular}{|c|c|c|c|c|}
\hline & $n$ & $\begin{array}{l}\text { Survivors } \\
(n=62)\end{array}$ & $\begin{array}{c}\begin{array}{c}\text { Non-survivors } \\
(n=8)\end{array} \\
\end{array}$ & $p$ \\
\hline & & $n[\%]$ & $n[\%]$ & \\
\hline \multicolumn{5}{|l|}{ Demographics and history } \\
\hline Gender (M/F) & 70 & $35 / 27$ & $4 / 4$ & 0.51 \\
\hline Age (years) & 70 & $57 \pm 19$ & $71 \pm 9$ & 0.04 \\
\hline $\begin{array}{l}\text { Underlying predisposing } \\
\text { condition for adverse course } \\
\text { of sepsis* }\end{array}$ & 70 & 39 [63\%] & 8 [100\%] & 0.42 \\
\hline Immunocompromised state ${ }^{* *}$ & 70 & 22 & 4 & 0.73 \\
\hline Nursing home resident & 70 & $1[2 \%]$ & 1 [12\%] & 0.24 \\
\hline Terminal illness & 70 & 1 [12\%] & 1 [12\%] & 0.24 \\
\hline \multicolumn{5}{|l|}{ Relevant medication use } \\
\hline Immunosuppressive drugs (n) & 70 & 19 [31\%] & 1 [12\%] & 0.68 \\
\hline Maintenance antibiotics ( $n$ ) & 70 & $5[8 \%]$ & 1 [12\%] & 0.54 \\
\hline$\beta$-blockers $(n)$ & 70 & 12 [19\%] & 6 [75\%] & $<0.01$ \\
\hline Other vasoactive medications & 70 & 18 [29\%] & 3 [38\%] & 0.71 \\
\hline Statins & 70 & 15 & 1 & 1.00 \\
\hline \multicolumn{5}{|l|}{ Site of infection } \\
\hline $\begin{array}{l}\text { Lower respiratory tract } \\
\text { infection }\end{array}$ & 70 & 35 & 6 & 0.77 \\
\hline Urinary tract infection & 70 & 10 & 2 & 0.64 \\
\hline Other & 70 & 17 & 0 & 0.35 \\
\hline \multicolumn{5}{|l|}{ Vital signs } \\
\hline $\begin{array}{l}\text { Altered mental state } \\
(\mathrm{GCS}<15)\end{array}$ & 70 & 0 & 1 & 0.13 \\
\hline Heart rate (bpm) & 70 & $109 \pm 18$ & $101 \pm 19$ & 0.34 \\
\hline Respiration rate (rpm) & 70 & $24 \pm 6$ & $22 \pm 5$ & 0.14 \\
\hline Temperature $\left({ }^{\circ} \mathrm{C}\right)$ & 70 & $38.3 \pm 1.0$ & $37.8 \pm 1.6$ & 0.32 \\
\hline $\mathrm{SBP}(\mathrm{mmHg})$ & 70 & $131 \pm 26$ & $132 \pm 30$ & 0.62 \\
\hline \multicolumn{5}{|l|}{$\mathrm{DBP}(\mathrm{mmHg})$} \\
\hline MAP (mmHg) & 70 & $91 \pm 16$ & $95 \pm 20$ & 0.84 \\
\hline Oxygen saturation (\%) & 70 & $94 \pm 4$ & $95 \pm 3$ & 0.58 \\
\hline \multicolumn{5}{|l|}{ Laboratory values } \\
\hline $\mathrm{Hb}\left(\right.$ mmol..$\left.^{-1}\right)$ & 70 & $7.7 \pm 1.4$ & $6.6 \pm 1.2$ & 0.03 \\
\hline $\mathrm{Ht}(\%)$ & 70 & $36 \pm 0.10$ & $35 \pm 0.09$ & 0.94 \\
\hline Platelet count $\left(\times 10^{9} . .^{-1}\right)$ & 69 & $251 \pm 160$ & $243 \pm 179$ & 0.77 \\
\hline $\begin{array}{l}\text { White blood cell count } \\
\left(\times 10^{9} . I^{-1}\right)\end{array}$ & 70 & $13.0 \pm 6.2$ & $8.5 \pm 4.7$ & 0.06 \\
\hline CRP $\left(m g . I^{-1}\right)$ & 70 & $110 \pm 98$ & $113 \pm 90$ & 0.90 \\
\hline Creatinine (umol..$^{-1}$ ) & 70 & $83 \pm 49$ & $79 \pm 20$ & 0.58 \\
\hline BUN $\left(m m o l . I^{-1}\right)$ & 70 & $6.3 \pm 3.3$ & $9.2 \pm 3.6$ & 0.14 \\
\hline Bilirubin (mmol..$^{-1}$ ) & 49 & $18 \pm 21$ & $21 \pm 12$ & 0.93 \\
\hline Glucose (mmol..$\left.^{-1}\right)$ & 61 & $7.2 \pm 2.5$ & $6.3 \pm 1.0$ & 0.23 \\
\hline Arterial lactate (mmol..$\left.^{-1}\right)$ & 45 & $1.1 \pm 0.5$ & $1.3 \pm 0.2$ & 0.57 \\
\hline
\end{tabular}

Table 1 Clinical and biochemical characteristics of survivors and non-survivors of uncomplicated sepsis at the emergency department (Continued)

\begin{tabular}{|c|c|c|c|c|}
\hline \multicolumn{5}{|l|}{ Treatment characteristics } \\
\hline Time to antibiotics (min) & 47 & $88 \pm 54$ & $80 \pm 51$ & 0.85 \\
\hline $\begin{array}{l}\text { Fluid administration first } \\
120 \mathrm{~min}(\mathrm{ml})\end{array}$ & 62 & $688 \pm 586$ & $625 \pm 627$ & 0.89 \\
\hline Abbrev. MEDS score & 70 & $4.8 \pm 2.9$ & $7.2 \pm 3.4$ & 0.03 \\
\hline \multicolumn{5}{|c|}{$\begin{array}{l}\text { Data are presented as mean } \pm \text { SD. GCS, Glasgow coma scale; SBP, systolic } \\
\text { blood pressure; MAP, mean arterial pressure; Hb, hemoglobin; CRP, C-reactive } \\
\text { protein; BUN, blood urea nitrogen. } \\
\text { *See Table } 2 \text {. } \\
\text { **Immunocompromised state was considered present if a patient had any of } \\
\text { the following: HIV or AIDS, leukemia, any malignancy, any history of } \\
\text { chemotherapy, neutropenic fever, non-Hodgkin's lymphoma, transplanted } \\
\text { organ, or current use of steroid or other immunosuppressive drugs. }\end{array}$} \\
\hline
\end{tabular}

ICU ward. An alternative explanation however might be that 56 out of 70 subjects in our study had co-morbidity potentially predisposing them to an adverse course of their sepsis, and 26 out of 70 subjects (37\%) were considered immunocompromised.

Previous studies identified various patient characteristics related to final outcome in patients with severe sepsis, and multiple risk prediction models have been developed to adequately risk stratify patients based on combinations of these characteristics [7]. Most commonly used, and the only model created to aid clinical decision making in the ED, is the MEDS score [3]. In our study we calculated abbreviated MEDS scores (without neutrophil bands, reflecting common practice in the Netherlands) as a measure of sepsis severity [6]. Even though the MEDS score was $<12$ for all subjects included in our study, we found that the average MEDS score was significantly higher in subjects with an adverse outcome $[7,8]$, which was mainly a reflection of the

Table 2 Co-morbidity of survivors and non-survivors of uncomplicated sepsis at the emergency department

\begin{tabular}{|c|c|c|c|}
\hline & $\begin{array}{c}\text { Survivors } \\
(n=62) \\
\end{array}$ & $\begin{array}{c}\text { Non-survivors } \\
(n=8)\end{array}$ & $p$ \\
\hline & $n[\%]$ & $n[\%]$ & \\
\hline Active malignancy & 7 & 4 & 0.02 \\
\hline -With metastasis & 1 & 1 & 0.22 \\
\hline Status after organ transplantation & 7 & 1 & 0.64 \\
\hline CAD or urinary tract abnormalities & 6 & 1 & 0.59 \\
\hline Structural bile-duct abnormalities & 5 & 0 & 0.54 \\
\hline Heart failure & 11 & 3 & 0.19 \\
\hline Diabetes mellitus & 10 & 1 & 0.63 \\
\hline $\begin{array}{l}\text { Chronic obstructive pulmonary } \\
\text { disease }\end{array}$ & 12 & 3 & 0.27 \\
\hline Cystic fibrosis & 1 & 0 & 0.89 \\
\hline Wegener's granulomatosis & 1 & 0 & 0.89 \\
\hline
\end{tabular}


difference in age between both groups. In our study, however, the non-survivors differed from the survivors also in respect to various parameters not included in the MEDS score. First, subjects with an adverse outcome invariably had an underlying predisposing medical condition for their sepsis. Second, they more often used beta-blockers compared to survivors. This finding is in line with several experimental animal studies that do report an increased overall sepsis mortality in betablocker subgroups [9] despite the well-known positive effects of beta-blockers on glucose modulation, the host immune response and sepsis-related cardiac dysfunction [10]. This might be explained by the masking effects of beta-blocker use on tachycardia, resulting in underestimation of sepsis severity and lack of adequate resuscitation. Finally, the group non-survivors had a significantly lower $\mathrm{Hb}$, even after correction for the age difference. Theoretically, this could be explained partially by differences in pre-hospital fluid administration, since this parameter was not recorded in the present study. From previous studies, however [11], we know that administration of 21 normal saline in $1 \mathrm{~h}$ results in only a $7.5 \%$ decrease in $\mathrm{Hb}$ and $\mathrm{Ht}$. So, it is highly unlikely that pre-hospital fluid administration alone accounts for the reported difference in $\mathrm{Hb}$. Since oxygen delivery is partially dependent on available $\mathrm{Hb}$, the lower the $\mathrm{Hb}$, the earlier relative tissue hypoxia will occur, especially in a hypermetabolic state such as sepsis. This finding supports the recommendation of administration of blood in sepsis patients with a $\mathrm{ScvO}_{2}$ of less than $70 \%$ when other resuscitative methods have already been applied [4].

In our study, the mean time to antibiotics was $87 \mathrm{~min}$, which is less than Barochia et al. [12] reported in a recent meta-analysis investigating the effect of the introduction of "sepsis bundles." Fluid resuscitation in our study was comparable to what De Miguel-Yanes et al. [13] recently reported in an observational study of patients with uncomplicated sepsis at the ED.

Our findings are of high clinical relevance, since recently Glickman et al. demonstrated that ine out of five patients visiting the ED with uncomplicated sepsis progress to severe sepsis or even septic shock within $72 \mathrm{~h}$ [14]. Early identification of risk factors creates an opportunity to tailor individual treatment in patients presenting with uncomplicated sepsis in order to prevent disease progression.

\section{Limitations}

Since the prospective quality improvement initiative to improve early sepsis recognition in patients with sepsis at the ED ran only 3 months, only 70 subjects were included, and a total of 8 events were recorded. This relatively small sample size of our study precludes drawing solid conclusions regarding causality: Except for betablocker use, the study had insufficient power to detect univariate correlations of outcome with age, underlying predisposing medical condition, MEDS score, $\mathrm{Hb}$ and other clinical and biochemical parameters. Future studies with larger sample sizes should therefore be carried out to address this. As with any retrospective study, the data included and their accuracy are dependent on the original ED documentation. Since no formal data collection protocol was used, important data regarding treatment characteristics of our patient population (e.g., time to antibiotics and the amount of fluid and oxygen administration) were unavailable or incomplete for a significant number of patients at the moment of chart review.

\section{Conclusions}

Non-survivors of uncomplicated sepsis had on average a higher abbreviated MEDS score, a lower $\mathrm{Hb}$ and more often used beta-blockers compared to survivors. Early identification of the presence of these factors might contribute to optimization of sepsis treatment for this patient category and thereby prevent disease progression to severe sepsis or septic shock.

\section{Abbreviations}

MEDS score: Mortality in Emergency Department Sepsis score

ED: Emergency department; SIRS: Systemic inflammatory response syndrome.

\section{Competing interests}

The authors declare that they have no competing interests.

\section{Authors' contributions}

EtA designed the study; EtA, MdJ and IB were involved with data collection. EtA was primary author. GW and JtM were secondary authors and editors of the manuscript. All authors read and approved the final manuscript.

\section{Author details}

'Department of Emergency Medicine, Medical Center Leeuwarden, Henry Dunantweg 2, Leeuwarden 8934 AD, The Netherlands. ${ }^{2}$ Department of Emergency Medicine, University Medical Center Groningen, Groningen, The Netherlands. ${ }^{3}$ Department of Anaesthesiology, University Medical Center Groningen, Groningen, The Netherlands.

Received: 18 October 2012 Accepted: 10 March 2013

Published: 8 April 2013

\section{References}

1. Majuran M, Clancy M: Determination of the size of the different sepsis categories presenting to a UK teaching hospital emergency department. Emerg Med J 2008, 25:11-14.

2. Dombrovskiy VY, Martin AA, Sunderram J, Paz HL: Rapid increase in hospitalization and mortality rates for sever sepsis in the United States: A trend analysis from 1993 to 2003. Crit Care Med 2007, 35:1244-1250.

3. Shapiro NI, Wolge RE, Moore RB, Smith E, Burdick E, Bates DW: Mortality in emergency department sepsis (MEDS) score: a prospectively derived and validated clinical prediction rule. Crit Care Med 2003, 31:670-675.

4. Rivers E, Ngyuen B, Havstad S, Ressler J, Muzzin A, Peterson E, et al: Early goal directed therapy in the treatment of severe sepsis and septic shock. N Engl J Med 2001, 345:1368-1377.

5. Howell MD, Talmor D, Schuetz P, Hunziker S, Jones AE, Shapiro NI: Proof of principle: the predisposition, infection, response, organ failure sepsis staging system. Crit Care Med 2011, 39:322-327. 
6. Vorwerk C, Loryman B, Coats TJ, Stephenson JA, Gray LD, Reddy G, et al: Prediction of mortality in adult emergency department patients with sepsis. Emerg Med J 2009, 26:254-258.

7. Chen CC, Chong CF, Liu YL, Chen KC, Wang TL: Risk stratification of severe sepsis patients in the emergency department. Emerg Med J 2006, 23:281-285.

8. Hermans MA, Leffers P, Jansen LM, Keulemans YC, Stassen PM: The value of the Mortality in Emergency Department Sepsis (MEDS) score, C-reactive protein and lactate in predicting 28-day mortality of sepsis in a Dutch emergency department. Emerg Med J 2012, 29:295-300.

9. Schmitz D, Wilsenack K, Lendemanns S, Schedlowski M, Oberbeck R: Beta-adrenergic blockade during systemic inflammation: impact on cellular immune functions and survival in a murine model of sepsis. Resuscitation 2007, 72:286-294.

10. Novotny NM, Lahm T, Markel TA, et al: [Beta]-blockers in sepsis: reexamining the evidence. Shock 2009, 31:113-119.

11. Lobo DN, Stanga Z, Simpson JA, Anderson JA, Rowlands BJ, Allison SP: Dilution and redistribution effects of rapid 2-Litre infusions of $0.9 \%(\mathrm{w} / \mathrm{v})$ saline and $5 \%(\mathrm{w} / \mathrm{v})$ dextrose on haematological parameters and serum biochemistry in normal subjects: a double-blind crossover study. Clin Sci 2001, 101:173-179.

12. Barochia AV, Cui X, Vitberg D, Suffredini AF, O'Grady NP, Banks SM, et al: Bundled care for septic shock: an analysis of clinical trials. Crit Care Med 2010, 38:668-678.

13. De Miguel-Yanes JM, Muñoz-González J, Andueza-Lillo JA, Moyano-Villaseca B, González-Ramallo VJ, Bustamante-Fermosel A: Implementation of a bundle of actions to improve adherence to the Surviving Sepsis Campaign guidelines at the ED. Am J Emerg Med 2009, 27:668-674

14. Glickman SW, Cairns CB, Otero RM, Woods CW, Tsalik EL, Langley RJ, et al: Disease progression in hemodynamically stable patients presenting to the emergency department with sepsis. Acad Emerg Med 2010, 17:383-390.

doi:10.1186/1865-1380-6-9

Cite this article as: ter Avest et al:: Outcome predictors of uncomplicated sepsis. International Journal of Emergency Medicine 2013 6:9.

\section{Submit your manuscript to a SpringerOpen ${ }^{\odot}$ journal and benefit from:}

- Convenient online submission

- Rigorous peer review

- Immediate publication on acceptance

- Open access: articles freely available online

- High visibility within the field

- Retaining the copyright to your article

Submit your next manuscript at $>$ springeropen.com 